SHORT REPORT

\title{
The $p 53$ codon 72 variation is associated with the age of onset of hereditary non-polyposis colorectal cancer (HNPCC)
}

\author{
S Krüger, A Bier, C Engel, E Mangold, C Pagenstecher, M von Knebel Doeberitz, E Holinski-Feder, \\ G Moeslein, K Schulmann, J Plaschke, J Rüschoff, H K Schackert, the German HNPCC Consortium
}

J Med Genet 2005;42:769-773. doi: 10.1136/jmg.2004.028506

The polymorphic variants at codon 72 of the $p 53$ gene were shown to be functionally distinct in vitro, whereby the arginine (arg) variant induces apoptosis more efficiently than the proline (pro) variant. From the evidence that the DNA mismatch repair system and p53 interact to maintain genomic integrity, we hypothesized that the codon 72 variation may influence the age of onset of disease in HNPCC patients. We tested 538 patients for p53 codon 72 variants, including 167 unrelated patients with pathogenic germline mutations in $\mathrm{MSH} 2$ or $\mathrm{MLH1}$ and colorectal carcinoma as first tumour, 126 patients with sporadic microsatellite stable colorectal cancers, and 245 healthy controls. The median age of onset was 41,36 , and 32 years for $\mathrm{MSH} 2$ or $\mathrm{MLH} 1$ mutation carriers with arg/arg, arg/pro, and pro/pro genotypes, respectively. The log rank test revealed significant differences in the age of onset between arg/arg and pro/pro individuals $(p=0.0002)$ and in arg/ pro versus arg/arg and pro/pro individuals $(p=0.0026$ and $p=0.0217$, respectively). A Cox regression model indicated an additive mode of inheritance. No significant differences in age of onset were observed among different genotype carriers with microsatellite stable tumours. Our results suggest that $p 53$ codon 72 genotypes are associated with the age of onset of colorectal carcinoma in a mismatch repair deficient background in a dose dependent manner. These findings may be relevant for preventive strategies in HNPCC.

$\mathrm{T}$ he tumour suppressor gene $p 53$ is known to play an important role in human carcinogenesis. $p 53$ mutations represent the most common genetic alterations in human cancers. Functional impairment of p53 is associated with chromosomal instability such as aneuploidy. After cellular stress, hypoxia, oncogene activation, or treatment with DNA damaging agents, p53 either induces cell cycle arrest for DNA repair or induces apoptosis. ${ }^{1}$ p53 is involved in at least three of five major DNA repair pathways, ${ }^{2}$ and has also been shown to bind insertion/deletion loops of DNA. ${ }^{3}$ As a consequence of mutations in $p 53$, genetic alterations accumulate in the cell and result in malignant transformation. ${ }^{4}$

Exon 4 of $p 53$ harbours a common G/C nucleotide variation encoding the amino acids arginine (CGC) or proline (CCC) at codon 72 (arg72/pro72). The pro72 allele frequency shows a significant linear correlation with geographical latitude, ranging from 0.63 in Nigerians to 0.17 in Swedish Saamis. It has been suggested that the two alleles code for functionally distinct proteins and that the pro72 allele might be selected for in environments subjected to high levels of ultraviolet light. $^{5}$
Several studies have addressed the issue of whether this polymorphism is involved in the development of cancer. As the $\arg 72$ and pro72 variants differ in their susceptibility to degradation by human papilloma virus (HPV) E6 protein, ${ }^{6}$ the association between these variants and cancer risk has been studied in cervical cancer and in several other types of tumour, with controversial results. ${ }^{6-16}$ Recently, it has been shown that the polymorphic variants at codon 72 of $p 53$ are functionally distinct in vitro, whereby the $\arg 72$ variant induces apoptosis more efficiently than the pro72 variant. The data suggest that at least one source of this apoptotic potential is the greater ability of the $\arg 72$ variant to localise to the mitochondria, and thus to be associated with p53 dependent apoptosis. ${ }^{17}$

Hereditary nonpolyposis colorectal cancer (HNPCC) is one of the most common colorectal cancer susceptibility syndromes, with an autosomal dominant mode of inheritance and incomplete penetrance. In the majority of cases, it is caused by germline mutations in the DNA mismatch repair (MMR) genes MSH2, MLH1, MSH6, and PMS2, with most of the mutations occurring in $\mathrm{MSH} 2$ and $M L H 1 .{ }^{18}$ Mutation carriers have an increased risk of developing colorectal carcinoma, and extracolonic neoplasias such as endometrial, small bowel, ureter/renal pelvis, stomach, ovary, and hepatobiliary cancer. ${ }^{19}{ }^{20}$ Therefore, a specific surveillance program for early detection of tumours is recommended for these patients.

A hallmark of HNPCC malignancies is the contraction/ expansion of simple DNA sequence motifs, a process termed microsatellite instability (MSI). ${ }^{21}$ The Bethesda guidelines, which include family history, and number and age of onset of HNPCC associated tumours, are recommended for the identification of patients with tumours with high MSI (MSI-H) ${ }^{22}$ In addition to an incomplete penetrance of about $80 \%$ for colorectal cancers and the broad tumour spectrum, a wide variety of age of onset of disease ranging from 16 to 90 years has been described. ${ }^{23}$ To date, the only genetic factors that have been reported in association with the age of onset of HNPCC are a common variant in the cyclin Dl gene ${ }^{24}$ and the mutant status of NAT2*7, one of several isozymes of $N$-acetyltransferase. ${ }^{25}$

In contrast to microsatellite instability, which is a feature of malignancies associated with MMR deficiency, most of the sporadic colorectal carcinomas show chromosomal instability frequently associated with loss of p53 and the development of aneuploidy. ${ }^{26}$ However, there is also evidence that the MMR system and p53 interact to maintain genomic integrity. For example, in vitro analysis of the $M L H 1$ deficient colorectal cancer cell line HCT-116 indicates that p53 can cooperate with the mismatch repair system in protecting cells from DNA damage. ${ }^{27}$ In addition, it has been suggested that $M L H 1$ deficient cells seem to be more dependent on the protective 
effect of p53 than MMR proficient HCT-116 cells in which $\mathrm{MLHl}$ function was restored. ${ }^{28}$ Similar findings have been reported for the ovarian cancer cell line A2780. ${ }^{29}$ Furthermore, studies in knockout mice provided evidence for a cooperation between MMR system and p53 in tumorigenesis. $^{3031}$

Therefore, we hypothesised that the arg72/pro72 variation in $p 53$ modulates the phenotype of neoplasias arisen from pathogenic germline mutations in mismatch repair genes. To exclude additional unknown exogenous and genetic factors that might modify penetrance, we studied only patients who had developed colorectal cancer. We show a significant association between the $p 53$ codon 72 variation and the age of onset of first manifestation of colorectal cancer in HNPCC patients, but lack of association in individuals with microsatellite stable tumours. These findings support the notion of a cooperation between p53 and the mismatch repair system in vivo.

\section{PATIENTS AND METHODS \\ Patients}

We studied 167 unrelated HNPCC patients consecutively registered at the clinical centres Bochum, Bonn, Düsseldorf, Dresden, Heidelberg, and Munich Regensburg of the German HNPCC Consortium. Bethesda criteria were applied as inclusion criteria. In addition, four patients with young age of onset of colorectal cancer or with a family history suspicious of HNPCC but who did not meet any of the Bethesda criteria were included. To avoid possible familial or genetic factors inducing a correlation in family members (besides the $p 53$ genotype), we included only one member per family. Of 167 individuals studied ( 103 men, 64 women), 157 were the nominal probands in their family. In the remaining 10 families, a colorectal cancer was not the first tumour presentation in the nominal proband, which was one of the requirements for inclusion in the study. Patients from these 10 families selected for the study were the earliest onset cases for colorectal cancer in their respective families. In all index patients from whom tumour material was available, microsatellite analyses and, in most cases, immunohistochemistry analyses of mismatch repair protein expression of at least MSH2 and MLH1 were performed. Aberrant findings such as MSI-H or lost or reduced expression of at least one MMR protein identified by immunohistochemistry led to mutation screening. In patients who fulfilled Amsterdam I/II criteria but for whom tumour material was not available, mutation screening in MSH2 and MLHI was performed without results for MSI or immunohistochemistry. All patients described here were carriers of germline mutations in either MSH2 (87 patients) or $M L H 1$ (80 patients), predicted to be pathogenic because of their nature as protein truncating small insertions/ deletions, large genomic rearrangements, nonsense, or splice site mutations. To control for the false inclusion of nonpathogenic missense mutations in MSH2 and $M L H 1$, we completely excluded carriers of such mutations.

The first tumour manifestation in all 167 patients was a colorectal carcinoma revealed by medical history and histopathological examination. Median age at diagnosis of colorectal cancer in all patients harbouring a MMR germline mutation was 39 years. Tumours of 142 of the 167 kindreds were analysed and revealed MSI-H. Microsatellites from the other 25 families were not analysed because tumour samples were not available. For MSI analysis, at least five markers according to the reference panel of the International Guidelines for Evaluation of MSI in Colorectal Cancer were applied. ${ }^{32}$ MSI-H was considered if at least 30\% of markers showed instabilities. Apart from the 167 HNPCC patients, 126 patients with sporadic tumours from Dresden were analysed using 15 microsatellite markers. ${ }^{33}$ Microsatellite stability
(MSS) was considered if none of the markers showed instability. Age of onset of disease was defined as the time of histological tumour diagnosis. All patients gave written informed consent for study participation. The controls were 245 anonymous healthy blood donors from the Dresden Regional Blood Center.

\section{Methods}

Genotyping of $p 53$ codon 72 was performed on genomic DNA isolated from peripheral blood lymphocytes by two independent methods as follows.

(1) PCR-amplification (Taq polymerase, Perkin Elmer Applied Biosystems, Weiterstadt, Germany) of exon 4 of p53 using primers $5^{\prime}$-TGAGGACCTGGTCCTCTGAC- $3^{\prime}$ and $5^{\prime}$ AGAGGAATCCCAAAGTTCCA-3', ${ }^{34}$ resulting in 412 bp fragments. The PCR-products were digested with the endonuclease BstUl (restriction site: $5^{\prime} \ldots \mathrm{CG}^{\boldsymbol{\nabla}} \mathrm{CG} \ldots 3^{\prime}, 3^{\prime} \ldots$ $\mathrm{CG}_{\mathbf{\Delta}} \mathrm{CG} \ldots 5^{\prime}$ ), which specifically cleaves the allele coding for $\arg 72$ (CGC) but not that for pro72 (CCC). Cleaved PCR products resulted in two fragments of $161 \mathrm{bp}$ and $251 \mathrm{bp}$. Fragments were analysed on an agarose gel.

(2) Most of the genotypes were confirmed by single base sequencing of PCR products using the Thermo Sequenase Fluorescent Cycle Sequencing kit and Automated Laser Fluorescence (ALF express) sequencing devices (both Amersham Pharmacia Biotech, Freiburg, Germany). Sequencing was performed with the Cy5 labelled antisense primer 5'-ATACGGCCAGGCATTGAAGT-3', ${ }^{34}$ using reagents from the Thermo Sequenase Fluorescent Cycle Sequencing kit that included cytosine, guanine, or both as dideoxynucleotide. To exclude the occurrence of a third variant, TGC, which codes for cysteine, ${ }^{35}$ all samples with at least one nondigested allele were screened by single base sequencing using the dideoxynucleotide adenine.

\section{Statistical analysis}

The age of onset of the first colorectal cancer was analysed by the Kaplan-Meier (product limit) method. The log rank test was applied to compare the age of onset between genotype groups. Firstly, a global comparison of all three groups was performed. Pairwise post hoc comparisons between the genotype groups were only performed after the global test revealed a significant difference. Multivariate Cox regression analysis was used to evaluate the role of the location of the MMR gene defect (MSH2 or MLHI) and to identify the possible mode of inheritance (additive versus dominant). The $\chi^{2}$ test was used to evaluate the homogeneity of genotype frequency distributions among the three groups of individuals. Genotype frequencies in all groups were cross checked with Hardy-Weinberg expectations by the $\chi^{2}$ test. Significance was set at $\mathrm{p}<0.05$. The statistical software package SPSS was used for all statistical data analyses.

\section{RESULTS}

Overall we found $330 \mathrm{arg} / \mathrm{arg}$ (61.3\%), $173 \mathrm{arg} /$ pro (32.2\%) and 35 pro/pro (6.5\%) genotypes. The compiled data analysis of the patients and controls is summarised in table 1 , and the distribution of genotypes in the two patient groups and in the control group are given in table 2 . We did not observe a significant difference in frequency of genotypes among these groups. Genotype frequencies in all groups were in accordance with those previously reported in Europe. ${ }^{8-12}{ }^{14}$ No significant deviations from Hardy-Weinberg equilibrium were detected (data not shown).

In patients with MMR germline mutations the median age of onset was 41 years for the arg/arg, 36 years for the arg/pro, and 32 years for the pro/pro individuals (table 3 ). The age of onset was significantly different between the three genotypes in the global comparison ( $\log$ rank, $\mathrm{p}<0.0001)$. All pairwise 


\begin{tabular}{|c|c|c|c|}
\hline & $\begin{array}{l}\text { MMR } \\
\text { mutation } \\
\text { carrier }\end{array}$ & $\begin{array}{l}\text { Sporadic } \\
\text { MSS }\end{array}$ & $\begin{array}{l}\text { Healthy } \\
\text { controls }\end{array}$ \\
\hline All & 167 & 126 & 245 \\
\hline \multicolumn{4}{|l|}{ Sex } \\
\hline Male & 103 & 74 & 113 \\
\hline Female & 64 & 52 & 132 \\
\hline \multicolumn{4}{|l|}{ MMR gene mutated } \\
\hline $\begin{array}{l}\text { MSH2 } \\
\text { MLH1 }\end{array}$ & $\begin{array}{l}87 \\
80\end{array}$ & & \\
\hline $\begin{array}{l}\text { Median age, in years, of } \\
\text { onset of CRC (range) }\end{array}$ & $\begin{array}{l}39 \\
(13-62)\end{array}$ & $\begin{array}{l}64 \\
(50-94)\end{array}$ & $\begin{array}{l}36 \\
(18-65)^{*}\end{array}$ \\
\hline \multicolumn{4}{|l|}{ Criterion } \\
\hline Amsterdam I/II & 99 & & \\
\hline Beth 2 & 3 & & \\
\hline Beth 2 and 4 & 6 & & \\
\hline Beth 2,3 , and 4 & 23 & & \\
\hline Beth 2,4 , and 7 & 1 & & \\
\hline Beth 3 and 4 & 14 & & \\
\hline Beth 3,4 , and 7 & 1 & & \\
\hline Beth 4 & 16 & & \\
\hline None & 4 & & \\
\hline
\end{tabular}

post hoc comparisons between the genotype groups revealed significant differences (arg/arg $v$ pro/pro $\mathrm{p}=0.0002$, $\arg / \arg v$ $\arg /$ pro $\mathrm{p}=0.0026$, arg/pro $v$ pro/pro $\mathrm{p}=0.0217$; see fig $1 \mathrm{~B}$ ).

We used a multivariate Cox regression analysis to investigate whether the age of onset depended on the location of the MMR gene defect (MLH1 versus MSH2) and whether the data could be explained assuming a dominant or an additive mode of inheritance. The hazard function in this model was defined as $h(t)=h_{0}(t) \exp \left(\beta_{1} G+\beta_{2} A+\beta_{3} D\right)$, where $G$ represents an indicator variable for the location of the MMR gene defect (coded as 1 for MLH1 and 2 for MSH2), A represents the number of pro alleles ( 0 for the arg/arg, 1 for the arg/pro, and 2 for the pro/pro genotype) which is a measure for the additivity of alleles, and D measures departure from additivity (that is, dominance, coded as 1 for the arg/pro genotype and 0 for the arg/arg and pro/pro genotypes). The result of the regression analysis showed that the location of the MMR gene defect was not a significant predictor $\left(\beta_{1}=-0.151, p=0.342\right)$. The effect of covariate $A$ was significant $\left(\beta_{2}=-0.609, p<0.001\right)$; however, no significant deviation from additivity could be found $\left(\beta_{3}=-0.108, p=0.604\right)$.

In contrast, no significant differences in the age of onset among the $p 53$ genotype carriers were observed in the patients with sporadic microsatellite stable colorectal cancers ( $\log$ rank, $\mathrm{p}=0.2096$ ). The median age of onset was 65 years in the arg/arg, 62 years in the arg/pro, and 61 years in the pro/pro individuals (table 3 ).

\section{DISCUSSION}

We observed a significant association between $p 53$ codon 72 variants and age of onset of colorectal cancers in patients with MSH2 and MLH1 germline mutations in a dose dependent manner, but not in patients with microsatellite stable tumours. Notably, a cooperation between MMR system and $p 53$ in tumorigenesis has been reported in knockout mice. Animals nullizygous for both Msh2 and $p 53\left(M_{s h} 2^{-/-}\right.$, $p 53^{-1-}$ ) had a significantly reduced median survival time compared with Msh2 deficient animals $\left(\mathrm{Msh}^{-1-}, \mathrm{p53}^{+/+}\right) .^{30} 31$ Furthermore, Toft et al found a significantly reduced survival of Msh2 deficient mice heterozygous for $p 53\left(M_{s h} 2^{-/-}, p 53^{+/}\right.$ -) compared with Msh2 deficient mice proficient for $p 53$ $\left(M s h 2^{-/-}, p 53^{+/+}\right)$and suggested a dose sensitive role of $\mathrm{p} 53$ in the maintenance of genomic integrity at the nucleotide
Table 2 Genotype frequencies in all patient groups and controls ( $C R C=$ colorectal cancer)

\begin{tabular}{|c|c|c|c|c|c|c|c|}
\hline & \multirow[b]{2}{*}{$\mathbf{n}$} & \multicolumn{2}{|c|}{ pro/pro } & \multicolumn{2}{|c|}{ arg/pro } & \multicolumn{2}{|c|}{ arg/arg } \\
\hline & & $n$ & $\%$ & $n$ & $\%$ & $n$ & $\%$ \\
\hline All genotypes & 538 & 35 & 6.5 & 173 & 32.2 & 330 & 61.3 \\
\hline Healthy controls & 245 & 17 & 7.0 & 78 & 31.8 & 150 & 61.2 \\
\hline $\begin{array}{l}\text { Sporadic MSS CRC } \\
\text { carriers }\end{array}$ & 126 & 6 & 4.8 & 41 & 32.5 & 79 & 62.7 \\
\hline $\begin{array}{l}\text { MMR mutation } \\
\text { carrier with CRC }\end{array}$ & 167 & 12 & 7.2 & 54 & 32.3 & 101 & 60.5 \\
\hline
\end{tabular}
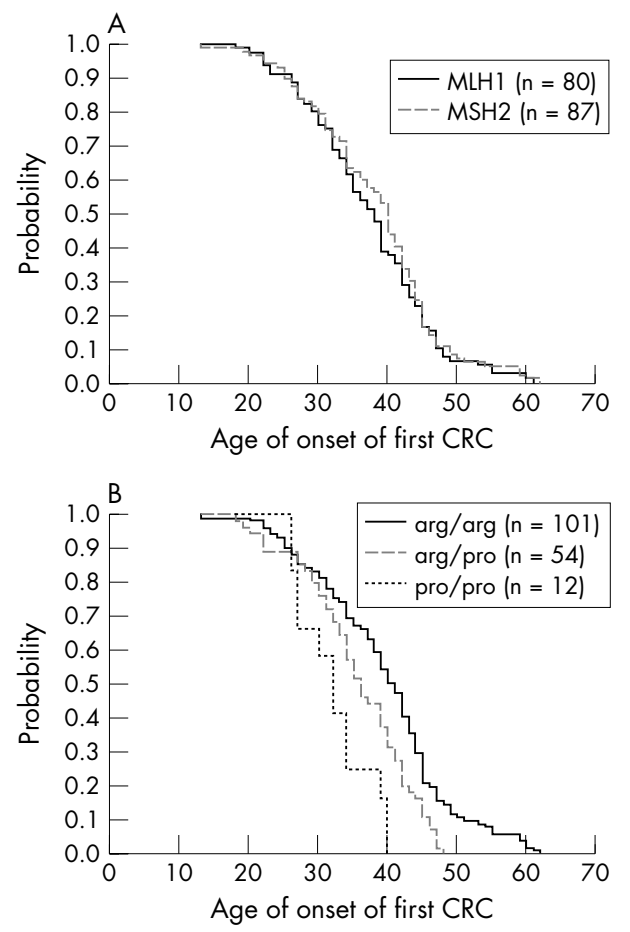

Figure 1 Age of onset of the first CRC in patients with pathogenic MMR germline mutations and different genotypes of the p53 codon 72 variants ( $n=167$ ) (A) Kaplan-Meier analysis with the location of the MMR gene defect as grouping variable. Cox regression analysis did not reveal a significant influence of the location of the MMR gene defect on age of onset. (B) Kaplan-Meier analysis with genotypes of the p53 codon 72 variants as grouping variable. The age of onset was significantly different among the three genotype groups (global $p<0.0001$ ) and in all pairwise comparisons (aarg/arg $\vee$ pro/pro $p=0.0002$, arg/arg $\vee$ arg/ pro $p=0.0026$, arg $/$ pro v pro/pro $p=0.0217$ ). Cox regression analysis indicated an additive mode of inheritance.

Table 3 Age of onset of colorectal cancer (in years)

\begin{tabular}{llll}
\hline & pro/pro & arg/pro & arg/arg \\
\hline Sporadic MSS, median age & 61 & 62 & 65 \\
(95\% Cl) & $(54$ to 68$)$ & $(59$ to 65$)$ & (62 to 68) \\
MMR mutation carrier, median & 32 & 36 & 41 \\
age (95\% Cl) & $(29$ to 35$)$ & $(33$ to 39$)$ & (39 to 43) \\
\hline
\end{tabular}

level. ${ }^{31}$ Notably, young age of onset is associated with a poorer 5 year survival rate in patients with highly unstable colorectal cancers. ${ }^{36}$

Very recently, another study with a different design but similar results was published by others. ${ }^{37}$ In contrast to our 
study, 92 MSH2 or MLH1 mutation carriers from 47 families were included, and 16 families were represented by more than one member (range 2-8). In addition to 62 subjects with truncation or deletion mutations, 30 (32.6\%) missense mutation carriers were also analysed. Of the 92 individuals studied, 47 had colorectal cancer and 45 (48.9\%) were unaffected MMR mutation carriers. As with our study, the authors found a significantly earlier median age of onset in individuals who were heterozygous (arg/pro) than in those who were homozygous for the wild type (arg/arg) p53 allele. Only seven subjects were homozygous for the polymorphic p53 allele (pro/pro) and only one of these had colorectal cancer (at 63 years of age). According to the authors, this number was too small to provide meaningful results. For this reason, a dose dependent effect of the variant $p 53$ allele could not been shown.

We did not observe significant differences in genotype frequencies between the two groups of colorectal cancer patients and controls, suggesting that the $p 53$ codon 72 variation is not involved in tumour initiation. This finding is in accordance with several studies that failed to detect an association between the occurence of malignancies and the $p 53$ codon 72 variation in various tumour types including colorectal cancers, ${ }^{7-13} 1516$ although others reported quite opposite results. ${ }^{6} 14$

One substantial difference between the experiments in mice and our clinical study is that although both approaches used an MMR deficient background, the animal experiments studied inactivating mutations of $p 53$, while we analysed $p 53$ variants differing in their potential to induce apoptosis. ${ }^{17}$ Notably, we still observed a linear trend in the age of onset across genotype groups in colorectal cancer patients with MMR deficiency. These findings suggest that the mode of action of p53 in a mismatch repair deficient background is the induction of apoptosis in developing tumours. ${ }^{17} 38$

We therefore postulate that the different apoptotic potentials of the $p 53$ codon 72 variants modify the disease phenotype, and that the high apoptosis variant $\arg 72$ mediates the destruction of MSI-H tumours more efficiently than the low apoptosis variant pro72. There is a high probability in HNPCC patients of developing synchronous and/or metachronous tumours during their lifetime. ${ }^{20}$ However, more "attempts" to develop a tumour may be required in carriers of the high apoptosis $p 53$ variant than in those who carry the low apoptosis variant. Given the almost linear risk increase of developing an HNPCC tumour during a lifetime, ${ }^{23}$ the more "attempts" needed to develop a tumour, the later the clinical manifestation.

As $p 53$ is involved in numerous cellular pathways related to carcinogenesis through multiple, complex interactions that are only partially understood, other possible mechanisms should be considered. For example, another explanation for the observed association between the $p 53$ codon 72 variants and age of onset in patients with MSI-H tumours, but not in patients with MSS tumours, could be that microsatellite stable colorectal cancers more frequently exhibit somatic alterations in $p 53$ with loss of function than highly microsatellite unstable cancers. ${ }^{39}$ Thus, inherited variants in $p 53$, such as the codon 72 polymorphism, would have a minor impact in patients with MSS tumours. MMR insufficient cells may also be more dependent on the $p 53$ mediated apoptotic pathway, as the MMR system itself seems to play a potential role in apoptosis in a largely $p 53$ independent manner. ${ }^{2}$ In addition, a dose sensitive role for $p 53$, resulting in suppression of MSI in the absence of Msh2, has been considered at the nucleotide level in a mouse model. ${ }^{31}$ Furthermore, $p 53$ deficient cells are incapable of damage induced Gl/S checkpoint arrest, which may result in slower tumour growth. $^{40}$
If independently corroborated by prospective cohort studies, the observed effect of the $p 53$ codon 72 variation on the age of onset in HNPCC should be robust in populations with different allele frequencies in various regions of the northern hemisphere. Similarly, it can also be inferred that the median age of onset of HNPCC in populations with a high allele frequency of the pro72 variant such as Nigerians or African Americans will be lower than in white populations.

In conclusion, our data support the notion that colorectal cancer is a multifactorial disease. $p 53$ codon 72 variants, in conjunction with other modifying factors such as cyclin DI polymorphism, NAT2*7, and additional exogenous and genetic factors may contribute to a more detailed tumour risk assessment in MMR gene mutation carriers.

The knowledge of the age of onset of disease in individual carriers of pathogenic MMR germline mutations may have an impact on preventive strategies, including the age at first surveillance, surveillance intervals, and age at preventive surgery.

\section{ACKNOWLEDGEMENTS}

We thank M Krenz and A Schiewart for excellent technical assistance. This work was supported by the Verbundprojekt "Familiärer Darmkrebs" of the Deutsche Krebshilfe (DKH, German Cancer Aid, 70-3032).

The German HNPCC-Consortium consists of the following centres (in alphabetical order). Clinical centres in Bochum (in addition to author: F Brasch, JT Epplen, S Hahn, E Kunstmann, C Pox, W Schmiegel, J Willert), Bonn (in addition to authors: R Büttner, W Friedl, A Hirner, C Lamberti, M Mathiak, P Propping, T Sauerbruch), Düsseldorf (in addition to author: T O Goecke, A Hansmann, S Höwer, C Poremba, A Unger, T Vogel, C Wieland), Dresden (in addition to authors: D E Aust, F Balck, R Höhl, F R Kreuz, E Kuhlisch, S R Pistorius), Heidelberg (in addition to author: A Buckowitz, J Gebert, P Kienle, M Kloor, H P Knäbel, U Mazitschek, C Sutter), and München/Regensburg (in addition to author: W Dietmaier, M Gross, R Kopp, P Lohse, M Muders, Y Müller-Koch, $\mathrm{H}$ Vogelsang); Center for Reference Pathology, Kassel (in addition to author: T Brodegger); and Center for Documentation and Biometry, Leipzig (in addition to author: J Forberg, M Herold, M Löffler).

\section{Authors' affiliations}

S Krüger, J Plaschke, H K Schackert, Department of Surgical Research, Dresden University of Technology, Fetscherstraße 74, D-01307 Dresden, Germany

A Bier, Institute of Clinical Genetics, Dresden University of Technology, Fetscherstraße 74, D-01307 Dresden, Germany

C Engel, Institute for Medical Informatics, Statistics and Epidemiology, University of Leipzig, Liebigstrasse 27, D-04103 Leipzig, Germany

E Mangold, C Pagenstecher, Institute of Human Genetics, University Hospital Bonn, Wilhelmstraße 31, D-53111 Bonn, Germany

$M$ von Knebel Doeberitz, Institute of Molecular Pathology, University of Heidelberg, Im Nevenheimer Feld 220/221, D-69120 Heidelberg, Germany

E Holinski-Feder, Department of Medical Genetics, University of Munich, Goethestrasse 29, D-80336 Munich, Germany

G Moeslein, Department of Surgery, Heinrich-Heine-University

Duesseldorf, Moorenstraße 5, D-40225 Duesseldorf, Germany

K Schulmann, Ruhr University Bochum, Medical Department,

Knappschaftskrankenhaus, In der Schornau 23-25, D-44892 Bochum,

Germany

J Rüschoff, Institute of Pathology, Klinikum Kassel, Moenchebergstrasse 41-43, D-34125 Kassel, Germany

Competing interests: none declared

Correspondence to: Dr S Krüger, Department of Surgical Research, Dresden University of Technology, Fetscherstraße 74, D-01307

Dresden, Germany; e-mail: stefan.krueger@mailbox.tu-dresden.de

Received 21 October 2004

Revised version received 23 December 2004

Accepted for publication 27 December 2004 


\section{REFERENCES}

1 Levine AJ. p53, the cellular gatekeeper for growth and division. Cell 1997;88:323-31.

2 Bernstein C, Bernstein H, Payne CM, Garewal H. DNA repair/pro-apoptotic dual-role proteins in five major DNA repair pathways: fail-safe protection against carcinogenesis. Mutat Res 2002;511:145-78.

3 Lee S, Elenbaas B, Levine A, Griffith J. p53 and its 14 kDa C-terminal domain recognize primary DNA damage in the form of insertion/deletion mismatches. Cell 1995:81:1013-20.

4 Hainaut P, Hollstein M. p53 and human cancer: the first ten thousand mutations. Adv Cancer Res 2000;77:81-137.

5 Beckman G, Birgander R, Sjalander A, Saha N, Holmberg PA, Kivela A, Beckman $L$. Is $p 53$ polymorphism maintained by natural selection? Hum Hered 1994:44:266-70.

6 Storey A, Thomas M, Kalita A, Harwood C, Gardiol D, Mantovani F, Brever J, Leigh IM, Matlashewski G, Banks L. Role of a p53 polymorphism in the development of human papillomavirus-associated cancer. Nature 1998;393:229-34.

7 Rosenthal AN, Ryan A, Al-Jehani RM, Storey A, Harwood CA, Jacobs IJ. p53 codon 72 polymorphism and risk of cervical cancer in UK. Lancet 1998;352:871-2.

8 Lanham S, Campbell I, Watt P, Gornall R. p53 polymorphism and risk of cervical cancer. Lancet 1998;352:1631.

9 Hayes VM, Hofstra RM, Buys CH, Hollema H, van der Zee AG. Homozygous arginine 72 in wild type p53 and risk of cervical cancer. Lancet 1998;352: 1756.

10 Helland A, Langerod A, Johnsen H, Olsen AO, Skovlund E, Borresen-Dale AL. p53 polymorphism and risk of cervical cancer. Nature 1998:396:530-1.

11 Josefsson AM, Magnusson PK, Ylitalo N, Quarforth-Tubbin P, Ponten J, Adami HO, Gyllensten UB. p53 polymorphism and risk of cervical cancer. Nature 1998;396:531.

12 Hildesheim A, Schiffman M, Brinton LA, Fraumeni JF Jr, Herrero R, Bratti MC, Schwartz P, Mortel R, Barnes W, Greenberg M, McGowan L, Scott DR Martin M, Herrera JE, Carrington M. p53 polymorphism and risk of cervical cancer. Nature 1998;396:531-2.

13 Klaes R, Ridder R, Schaefer U, Benner A, von Knebel Doeberitz M. No evidence of p53 allele-specific predisposition in human papillomavirusassociated cervical cancer. J Mol Med 1999:77:299-302.

14 Zehbe I, Voglino G, Wilander E, Genta F, Tommasino M. Codon 72 polymorphism of p53 and its association with cervical cancer. Lancet 1999;354:218-19.

15 Birgander R, Sjalander A, Rannug A, Alexandrie AK, Sundberg MI, Seidegard J, Tornling G, Beckman G, Beckman L. p53 polymorphisms and haplotypes in lung cancer. Carcinogenesis 1995; 16:2233-6.

16 Sialander A, Birgander R, Athlin L, Stenling R, Rutegard J, Beckman L, Beckman G. P53 germ line haplotypes associated with increased risk for colorectal cancer. Carcinogenesis 1995;16:1461-4.

17 Dumont P, Leu JI, Della Pietra AC 3rd, George DL, Murphy M. he codon 72 polymorphic variants of p53 have markedly different apoptotic potential. Nat Genet 2003;33:357-65

18 Liu B, Parsons R, Papadopoulos N, Nicolaides NC, Lynch HT, Watson P, Jass JR, Dunlop M, Wyllie A, Peltomaki P, de la Chapelle A, Hamilton SR, Vogelstein B, Kinzler KW. Analysis of mismatch repair genes in hereditary non-polyposis colorectal cancer patients. Nat Med 1996;2:169-74.

19 Lynch HT, Smyrk TC, Watson P, Lanspa SJ, Lynch JF, Lynch PM, Cavalieri RJ, Boland CR. Genetics, natural history, tumour spectrum, and pathology of hereditary nonpolyposis colorectal cancer: an updated review. Gastroenterology 1993; 104:1535-49.

20 Vasen HF, Wijnen JT, Menko FH, Kleibeuker JH, Taal BG, Griffioen G, Nagengast FM, Meijers-Heijboer EH, Bertario L, Varesco L, Bisgaard ML, Mohr J, Fodde R, Khan PM. Cancer risk in families with hereditary nonpolyposis colorectal cancer diagnosed by mutation analysis. Gastroenterology 1996; 110:1020-7.

21 lonov Y, Peinado MA, Malkhosyan S, Shibata D, Perucho M. Ubiquitous somatic mutations in simple repeated sequences reveal a new mechanism for colonic carcinogenesis. Nature 1993;363:558-61.

22 Rodriguez-Bigas MA, Boland CR, Hamilton SR, Henson DE, Jass JR, Khan PM, Lynch H, Perucho M, Smyrk T, Sobin L, Srivastava S. A National Cancer Institute Workshop on Hereditary Nonpolyposis Colorectal Cancer Syndrome: meeting highlights and Bethesda guidelines. J Natl Cancer Inst 1997;89:1758-62.

23 Vasen HF, Stormorken A, Menko FH, Nagengast FM, Kleibeuker JH, Griffioen G, Taal BG, Moller P, Wiinen JT. MSH2 mutation carriers are at higher risk of cancer than MLH1 mutation carriers: a study of hereditary nonpolyposis colorectal cancer families. J Clin Oncol 2001; 19:4074-80

24 Kong S, Amos Cl, Luthra R, Lynch PM, Levin B, Frazier ML. Effects of cyclin D polymorphism on age of onset of hereditary nonpolyposis colorectal cancer. Cancer Res 2000;60:249-52.

25 Frazier ML, O'Donnell FT, Kong S, Gu X, Campos I, Luthra R, Lynch PM, Amos $\mathrm{Cl}$. Age-associated risk of cancer among individuals with $\mathrm{N}$ acetyltransferase 2 (NAT2) mutations and mutations in DNA mismatch repair genes. Cancer Res 2001;61:1269-71.

26 Lengaver C, Kinzler KW, Vogelstein B. Genetic instability in colorectal cancers. Nature 1997;386:623-7.

27 Vikhanskaya F, Colella G, Valenti M, Parodi S, D'Incalci M, Broggini M. Cooperation between p53 and hMLH1 in a human colocarcinoma cell line in response to DNA damage. Clin Cancer Res 1999;5:937-41.

28 Lin X, Ramamurthi K, Mishima M, Kondo A, Christen RD, Howell SB. P53 modulates the effect of loss of DNA mismatch repair on the sensitivity of human colon cancer cells to the cytotoxic and mutagenic effects of cisplatin. Cancer Res 2001;61:1508-16.

29 Brown R, Clugston C, Burns P, Edlin A, Vasey P, Vojtesek B, Kaye SB. Increased accumulation of p53 protein in cisplatin-resistant ovarian cell lines. Int J Cancer 1993;55:678-84.

30 Cranston A, Bocker T, Reitmair A, Palazzo J, Wilson T, Mak T, Fishel R. Female embryonic lethality in mice nullizygous for both Msh2 and p53. Nat Genet 1997; 17:114-18.

31 Toft NJ, Curtis L, Sansom OJ, Leitch AL, Wyllie AH, te Riele H, Arends MJ, Clarke AR. Heterozygosity for p53 promotes microsatellite instability and tumourigenesis on a Msh2 deficient background. Oncogene 2002;21:6299-306.

32 Boland CR, Thibodeau SN, Hamilton SR, Sidransky D, Eshleman JR, Burt RW, Meltzer SJ, Rodriguez-Bigas MA, Fodde R, Ranzani GN, Srivastava S. A national cancer institute workshop on microsatellite instability for cancer detection and familial predisposition: development of international criteria for the determination of microsatellite instability in colorectal cancer. Cancer Res 1998;58:5248-57

33 Kruger S, Plaschke J, Pistorius S, Jeske B, Haas S, Kramer H, Hinterseher I, Bier A, Kreuz FR, Theissig F, Saeger HD, Schackert HK. Seven novel MLHI and $\mathrm{MSH} 2$ germline mutations in hereditary nonpolyposis colorectal cancer. Hum Mutat 2002;19:82.

34 Lehman TA, Bennett WP, Metcalf RA, Welsh JA, Ecker J, Modali RV, Ullrich S, Romano JW, Appella E, Testa JR, Gerwin BI, Harris CC. p53 mutations, ras mutations, and p53-heat shock 70 protein complexes in human lung carcinoma cell lines. Cancer Res 1991;51:4090-6.

35 Matlashewski GJ, Tuck S, Pim D, Lamb P, Schneider J, Crawford LV. Primary structure polymorphism at amino acid residue 72 of human p53. Mol Cell Biol 1987;7:961-3.

36 Farrington SM, McKinley AJ, Carothers AD, Cunningham C, Bubb VJ, Sharp L, Wyllie AH, Dunlop MG. Evidence for an age-related influence of microsatellite instability on colorectal cancer survival. Int J Cancer 2002;98:844-50.

37 Jones JS, Chi X, Gu X, Lynch PM, Amos Cl, Frazier ML. p53 polymorphism and age of onset of hereditary nonpolyposis colorectal cancer in a Caucasian population. Clin Cancer Res 2004; 10:5845-9.

38 Toft NJ, Winton DJ, Kelly J, Howard LA, Dekker M, te Riele H, Arends MJ, Wyllie AH, Margison GP, Clarke AR. Msh2 status modulates both apoptosis and mutation frequency in the murine small intestine. Proc Natl Acad Sci USA 1999;96:391 1-15.

39 Olschwang S, Hamelin R, Laurent-Puig P, Thuille B, De Rycke Y, Li YJ, Muzeau F, Girodet J, Salmon RJ, Thomas G. Alternative genetic pathways in colorectal carcinogenesis. Proc Natl Acad Sci USA 1997;94:12122-7.

40 Baker SJ, Markowitz S, Fearon ER, Willson JK, Vogelstein B. Suppression of human colorectal carcinoma cell growth by wild-type p53. Science 1990;249:912-15.

41 Lin D, Shields MT, Ullrich SJ, Appella E, Mercer WE. Growth arrest induced by wild-type $\mathrm{p} 53$ protein blocks cells prior to or near the restriction point in late G1 phase. Proc Natl Acad Sci USA 1992;89:9210-14. 